Article

\title{
Cognitive Functioning: An Underlying Mechanism of Age and Gender Differences in Self-Assessed Risk Tolerance among an Aging Population
}

\author{
Muna Sharma and Swarn Chatterjee *(D) \\ Department of Financial Planning, Housing and Consumer Economics, University of Georgia, \\ Athens, GA 30602, USA; ms71343@uga.edu \\ * Correspondence: swarn@uga.edu
}

Citation: Sharma, M.; Chatterjee, S. Cognitive Functioning: An

Underlying Mechanism of Age and Gender Differences in Self-Assessed Risk Tolerance among an Aging Population. Sustainability 2021, 13, 2361. https://doi.org/10.3390/ su13042361

Academic Editor: Andreas Ihle

Received: 27 January 2021

Accepted: 16 February 2021

Published: 22 February 2021

Publisher's Note: MDPI stays neutral with regard to jurisdictional claims in published maps and institutional affiliations.

Copyright: (C) 2021 by the authors. Licensee MDPI, Basel, Switzerland. This article is an open access article distributed under the terms and conditions of the Creative Commons Attribution (CC BY) license (https:/ / creativecommons.org/licenses/by/ $4.0 /)$.

\begin{abstract}
Attitude toward risk plays a vital role in an individual's financial decision-making and well-being. Past studies have found significant association of age and gender with risk tolerance. However, studies on the factors affecting the underlying mechanism are scant. The purpose of this research is to test whether cognitive functioning mediates the association between age, gender, and self-assessed risk tolerance. Using the 2014 wave of the Health and Retirement Study, path analysis was conducted to test the hypothesized model. Results revealed a negative direct association between age and risk tolerance. Moreover, the study also found a lower level of risk tolerance in women. A bootstrap-based confidence interval revealed that a significant portion of the relationship between age and risk tolerance was mediated by cognition. However, the gender difference in risk tolerance was not explained by cognition. Financial planning practitioners and policymakers should understand the contribution of cognitive functioning toward the difference in risk tolerance in older populations and implement strategies to reinforce cognitive functioning to mitigate the adversity of a low level of risk tolerance.
\end{abstract}

Keywords: risk tolerance; age; gender; cognition; mediation

\section{Introduction}

Risk tolerance, conceptualized as the willingness to accept uncertainty in making financial decisions [1], is a fundamental topic for investigation in behavioral economics [2]. Risk tolerance of an individual plays a crucial role in the household's economic and financial decisions, affecting the financial sustainability of their portfolio upon retirement [3]. Attitude toward risk impacts an individual's economic decision making in a myriad of contexts (e.g., decisions about consumption, savings, investments, and labor force participation). For instance, investors who are more willing to take risks are also more likely to invest in risky assets, such as stocks, and earn more returns in the long term [3], which results in greater wealth accumulation over time [4]. However, investors with a lower level of risk tolerance make conservative decisions and invest in less risky assets, such as bonds, and earn lower returns. Findings from extant literature on household finance suggest that people with low risk tolerance, who refrain from investing in risky assets over time, may fail to reach their retirement savings goals. Conversely, people with a greater stock of financial risk tolerance are associated with engaging in more financially sustainable behavior by investing into riskier assets, such as equities and equities-based mutual funds, which results in greater wealth accumulation and sustainable retirement savings over time [5]. Overall, risk tolerance plays a significant role in maintaining the financial sustainability of households over time [6].

Individuals have varying levels of risk tolerance. Financial advisors, to provide suitable recommendations and work in the best interest of clients, may benefit from an adequate understanding of factors affecting their clients' risk tolerance. Age is one of the 
determinants of individual risk tolerance. There is a stereotype that people become less risk-tolerant and adopt more caution as they grow old [7]. The population in the United States is aging. The U.S. Census Bureau (2018) projected that those aged 65 years and older would outnumber children for the first time, reaching 78 million compared to 76.4 million individuals under the age of 18 in 2035 (the information on projections can be found in U.S. Census Bureau website https:/ / www.census.gov/newsroom/press-releases / 2018 /cb18-41-population-projections.html accessed on 7 September 2020). An aging society confronting the increased aggregate risk aversion calls for an adjustment in social security, employment, and retirement systems to sustain a large number of older people in the economy, which underscores the importance of this study.

There is also another common belief that women are less willing to take risks than men. If women are less willing to take risks than men, there could be implications for the financial wellbeing of women. For example, a lower willingness to take risks among women might be the cause of the under-representation of women in high-paying jobs that provide remunerations based on the company's performance and occupations [8]. In the investment world, financial advisors might underestimate women's risk tolerance and suggest conservative portfolios that produce a lower rate of return [9].

While previous studies have established a significant association between age and risk tolerance [10-14] as well as gender and risk tolerance [15-18], research unraveling the mechanism through which observed age and gender difference occurs in risk attitudes are limited. Psychological measures might be among several underlying mechanisms. Policymakers need to understand whether the preference toward risk is innately shaped by age and gender or whether these associations are mediated by other psychological measures that differ with age and gender. Mediation mechanisms have been increasingly used in behavioral psychology to understand the mechanism by which independent variables affect dependent variables. The mediation effect occurs when a third variable explains the relationship between the predictor and a response variable [19]. This study conjectures cognition as a factor that possibly affects risk tolerance and examines to what extent the relationship between age, gender, and risk tolerance can be explained by cognitive functioning. Theoretical studies and empirical evidence suggest that cognitive functioning declines with age $[20,21]$ and differs by gender [22-24]. In addition, studies also suggest that cognitive ability affects investment behavior $[25,26]$. Cognitive decline with age and cognitive difference in gender might explain the risk attitude among older individuals. This research contributes to a growing literature relating risk preference to psychological measures by exploring whether variations in willingness to take risks among individuals across age and gender can be accounted for by differences in cognitive functioning.

Findings from the present analysis suggest that risk tolerance level is lower in older women and decreases with age. A significant proportion of the total effect of age was mediated by cognitive functioning. Results of this study provide insights for policymakers and financial practitioners to implement strategies that would reinforce cognitive skills in the older population to match risk tolerance with their capacity to absorb market fluctuations and moderate the adversity of risk aversion.

Previous studies have indicated that risk tolerance differs by age and gender; cognition also differs among age and gender, which in turn influences risk tolerance. Henceforth, we propose that cognition functioning may serve as a mediator in the relationship between age, gender, and risk tolerance. A conceptual model for the study is displayed in Figure 1. We controlled for potential confounding factors in the model; however, this information is not shown in the figure for brevity. 


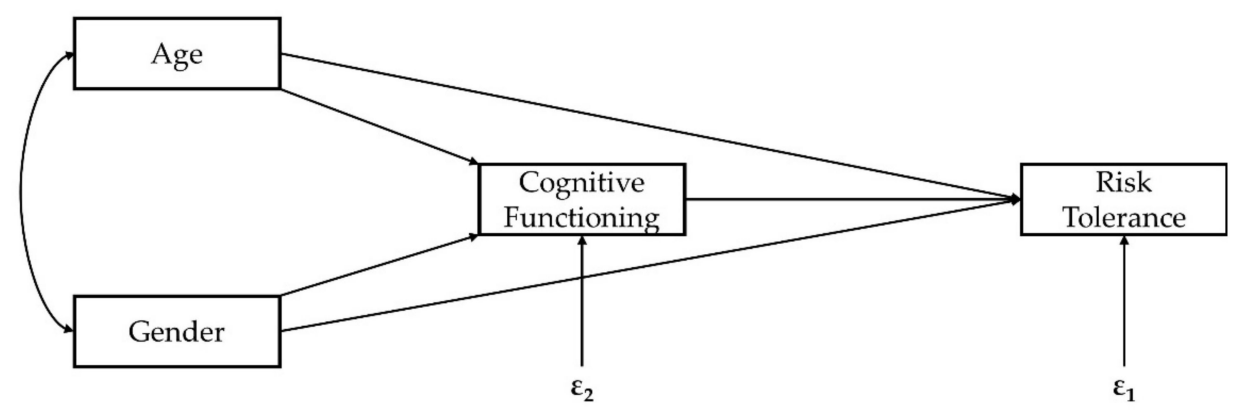

Figure 1. Conceptual model.

\section{Materials and Methods}

\subsection{Data}

This research relies upon the Health and Retirement Study (HRS). The HRS is a nationally representative survey of Americans over the age of 50, conducted by the Institute for Social Research at the University of Michigan and supported by the National Institute on Aging. The HRS is an extraordinarily rich dataset that provides researchers with the opportunity to investigate different aspects of population aging in the United States.

We used RAND-HRS Longitudinal File 2016, a user-friendly subset of the HRS, which contains cleaned and processed variables with consistent, intuitive naming conventions and model-based imputations that make the dataset handy. Since the cognitive score was available until 2014, the empirical analysis of this research draws upon the 2014 wave of the survey. Information on risk tolerance in the HRS was collected from respondents through the supplementary questionnaire, Question Concordance. We merged supplementary data of risk tolerance in 2014 to the RAND-HRS dataset. In our study, respondents were the unit of observation, and analysis used observations with complete information on risk tolerance, total cognition score, demographic background, self-reported health status, income, and wealth. In our study, we restricted the sample to respondents aged 65 or older, which resulted in a working sample of 9350 observations.

\subsection{Response Variable}

Risk tolerance in the survey was assessed using a single-item question, "Are you generally a person who tries to avoid taking risks or one who is fully prepared to take risks?" Respondents were asked to rate themselves from 0 to 10 , where 0 represents not at all willing to take risks, and 10 represents very willing to take risks.

\subsection{Covariates}

Age and gender were the primary variables of interest in our study. Age was included as a continuous variable and measured as the number of years from the respondent's birthdate and interview date. Gender was coded as 1 for female and 0 for male. Variable "cognition" in the RAND version was taken directly from the HRS imputations of cognitive functioning (please refer to the Health and Retirement Study Imputation of Cognitive Functioning Measures on the https://hrs.isr.umich.edu/sites/default/files/biblio/COGIMPdd.pdf for a more detailed description of the measures and the imputation process). The cognitive tasks in the HRS involved testing on the following items: (a) immediate word recall, (b) delayed word recall, (c) serial 7s, (d) counting backward from 20, (e) naming two objects: cactus and scissors, (f) naming the president and vice president of the US, and (g) naming the date of the survey. The scores on the first two items were summed to compute the total word recall score, which ranged from 0-20. Similarly, the mental status summary was a sum score of the remaining items in the list above and ranged from 0 to 15. An overall composite cognition score was used as a measure of cognitive functioning, which was the sum of the score on word recall and mental status.

Various demographic, socioeconomic, and health behaviors were included in the analysis as potential confounders. The marital status of respondents was classified into three cat- 
egories: single (never married), married (married/married, but spouse absent/partnered), and others (separated/divorced/widowed). Education level of respondents was coded as less than high school, high school graduates (high school graduates/GED/diploma), and college (some college/college and above). Race of respondents was categorized as: White (White/Caucasian), African American (Black/African American), and others. Ethnicity of respondents was coded as 1 for non-Hispanic and 0 for Hispanic. We included the self-reported health status of respondents to account for the confounding effect of health status, and it was coded as excellent, good (good/very good), fair, and poor health. The study also included total household income, net worth of non-housing financial wealth, and housing equity, and captured the income and wealth effect.

\subsection{Data Analysis}

A path analysis was conducted to investigate the relationship between age, gender, and cognition as predictors of risk tolerance. To explore the relationship between these variables, we first computed Pearson's correlation. Then, standardized regression coefficients were computed from path analysis, further disentangling the direct and indirect relationship between the variables. Bias-corrected bootstrapped confidence intervals were obtained to test the mediation effect. Under the path analysis framework, we tested the following hypothesis.

Hypothesis 1: Cognitive functioning mediates the relationship between age and risk tolerance.

Hypothesis 2: Cognitive functioning mediates the relationship between gender and risk tolerance.

\section{Results}

\subsection{Descriptive Statistics}

Table 1 presents the descriptive statistics of the variables used in the study. The sample was composed of people aged 65 and above. The average age in the sample was 75.6 years, with a maximum age of 104 years. Of the total sample, $59 \%$ were women. Around $81 \%$ of the sample were white people, $14 \%$ were African American, and the remaining $5 \%$ belonged to another races. Nearly $9 \%$ of the sample were Hispanic. Looking at the marital status, only $3 \%$ of the sample were single, who were never married, $58 \%$ were married, and the remaining 39\% were either separated, divorced, or widowed. Around $18 \%$ of the sample had less than a high school degree, $36 \%$ had a high school degree or GED or diploma, and $45 \%$ had made it to college or above college. Roughly $36 \%$ of the sample reported their health in excellent condition, $35 \%$ reported good or very good health condition, $22 \%$ reported fair health status, and the remaining $7 \%$ reported poor health status. The average income of the households was around 60 thousand. Similarly, average non-housing financial wealth and housing equity were around 169 and 149 thousand, respectively. On average, sample households had higher financial wealth than the housing equity. The sample also consisted of households with negative financial and housing wealth, who had more debt than their savings. The average cognition score of the sampled respondents was 5.31 , with a minimum score of 0 and a maximum score of 35 . Similarly, the average risk tolerance level in the sample was 5.59, the range being from 0 to 103 . 
Table 1. Descriptive statistics of variables used in the study.

\begin{tabular}{|c|c|c|c|c|c|c|}
\hline Variables & $\mathbf{M}$ & SD & Min & Max & Freq & $\%$ \\
\hline Age & 75.60 & 7.21 & 65.00 & 104.00 & - & - \\
\hline \multicolumn{7}{|l|}{ Gender } \\
\hline Male & - & - & - & - & 3819 & 40.84 \\
\hline Female & - & - & - & - & 5531 & 59.16 \\
\hline \multicolumn{7}{|l|}{ Race } \\
\hline White & - & - & - & - & 7594 & 81.22 \\
\hline African American & - & - & - & - & 1334 & 14.27 \\
\hline Others & - & - & - & - & 422 & 4.51 \\
\hline Ethnicity & - & - & - & - & & \\
\hline Hispanic & - & - & - & - & 835 & 8.93 \\
\hline Non-Hispanic & - & - & - & - & 8515 & 91.07 \\
\hline \multicolumn{7}{|l|}{ Marital status } \\
\hline Single & - & - & - & - & 271 & 2.90 \\
\hline Married & - & - & - & - & 5402 & 57.78 \\
\hline Others & - & - & - & - & 3677 & 39.33 \\
\hline \multicolumn{7}{|l|}{ Education } \\
\hline $\begin{array}{l}\text { Less than high } \\
\text { school }\end{array}$ & - & - & - & - & 1728 & 18.48 \\
\hline High school & - & - & - & - & 3401 & 36.37 \\
\hline College and above & - & - & - & - & 4221 & 45.14 \\
\hline \multicolumn{7}{|c|}{ Self-reported health status } \\
\hline Excellent & - & - & - & - & 3365 & 35.99 \\
\hline Good & - & - & - & - & 3281 & 35.09 \\
\hline Fair & - & - & - & - & 2063 & 22.06 \\
\hline Poor & - & - & - & - & 641 & 6.86 \\
\hline Income & $60,659.45$ & $108,263.80$ & 0.00 & $4,033,928.00$ & & \\
\hline Financial wealth & $169,141.80$ & $589,532.70$ & $-299,865.00$ & $1.58 \times 10^{7}$ & & \\
\hline Housing equity & $146,900.70$ & $242,632.70$ & $-80,4561.90$ & $7,627,460.00$ & & \\
\hline Cognition score & 21.37 & 5.31 & 0.00 & 35.00 & & \\
\hline Risk tolerance & 5.59 & 2.77 & 0.00 & 10.00 & & \\
\hline
\end{tabular}

Note. $n=9350 . \mathrm{M}=$ mean, $\mathrm{SD}=$ standard deviation.

\subsection{Pearson's Correlation}

The Pearson correlation in Table 2 reveals the relationships between age, gender, cognition, and risk tolerance. There existed a negative linear relationship between age and risk tolerance $(r=-0.066)$, showing that the average risk tolerance level decreased with age in the aging population. Gender was negatively linearly correlated $(r=-0.099)$ with the risk tolerance level, confirming that older women were generally less risk-tolerant than older men. A positive linear relationship $(r=0.094)$ existed between cognition score and risk tolerance among the aging population. Put differently, older individuals with higher cognition scores were more risk-tolerant than older individuals with lower cognition scores.

Table 2. Correlation among variables.

\begin{tabular}{ccccc}
\hline & Age & Gender & Cognition Score & Risk Tolerance \\
\hline Age & - & & & \\
Gender (Female $=1)$ & $0.014^{* * *}$ & - & & \\
Cognition score & $-0.337^{* * *}$ & $-0.042^{* * *}$ & - & - \\
Risk tolerance & $-0.066^{* * *}$ & $-0.099^{* * *}$ & $0.094^{* * *}$ & - \\
*** $^{*}<0.001$. & & &
\end{tabular}

\subsection{Path Analysis}

To further disentangle the direct and indirect relationships behind the bivariate correlations (presented in Table 2), we conducted a path analysis. Results of the path analysis are 
presented in Tables 3 and 4 . The final model had a moderate goodness of fit with chi-square $=529.36(\mathrm{df}=7, p<0.001), \mathrm{RMSEA}=0.089, \mathrm{CFI}=0.876, \mathrm{TLI}=0.446$, and SRMR $=0.035$.

Table 3. Standardized coefficients of path model for risk tolerance and cognition score.

\begin{tabular}{|c|c|c|c|}
\hline Outcomes & Predictors & $\beta$ & $95 \%$ CI for $\beta$ \\
\hline \multirow{20}{*}{ Risk tolerance } & Age & $-0.024 *$ & {$[-0.047,-0.001]$} \\
\hline & Gender $($ Female = 1) & $-0.166^{* * *}$ & {$[-0.207,-0.125]$} \\
\hline & Cognition score & $0.028 *$ & {$[0.003,0.055]$} \\
\hline & Race & & \\
\hline & White & $-0.106^{* *}$ & {$[-0.174,-0.033]$} \\
\hline & Others & -0.100 & {$[-0.227,0.036]$} \\
\hline & Ethnicity (Non-Hispanic $=1$ ) & $-0.152 * *$ & {$[-0.248,-0.057]$} \\
\hline & Marital status & & \\
\hline & Married & 0.029 & {$[-0.101,0.160]$} \\
\hline & Others & -0.025 & {$[-0.160,0.103]$} \\
\hline & Education & & \\
\hline & High school & 0.040 & {$[-0.032,0.110]$} \\
\hline & College and above & $0.221^{* * *}$ & {$[0.143,0.286]$} \\
\hline & Self-reported health & & \\
\hline & Excellent & $0.310^{* * *}$ & {$[0.212,0.410]$} \\
\hline & Good & $0.172^{* * *}$ & {$[0.078,0.268]$} \\
\hline & Fair & 0.023 & {$[-0.108,0.128]$} \\
\hline & Income (in thousands) & $0.035^{* * *}$ & {$[0.018,0.050]$} \\
\hline & Financial wealth (in millions) & 0.002 & {$[-0.016,0.018]$} \\
\hline & Housing equity (in thousands) & 0.004 & {$[-0.014,0.024]$} \\
\hline \multirow{10}{*}{ Cognition score } & Age & $-0.294 * * *$ & {$[-0.312,-0.275]$} \\
\hline & Gender $($ Female = 1) & $0.143^{* * *}$ & {$[0.109,0.176]$} \\
\hline & Education & & \\
\hline & High school & $0.650^{* * *}$ & {$[0.600,0.701]$} \\
\hline & College and above & $0.921^{* * *}$ & {$[0.871,0.972]$} \\
\hline & Self-reported health & & \\
\hline & Excellent & $0.548^{* * *}$ & {$[0.469,0.623]$} \\
\hline & Good & $0.445^{* * *}$ & {$[0.363,0.517]$} \\
\hline & Fair & $0.268^{* * *}$ & {$[0.182,0.346]$} \\
\hline & Income (in thousands) & $0.079^{* * *}$ & {$[0.060,0.095]$} \\
\hline
\end{tabular}

Note. $n=9350$. Confidence intervals (CI) are based on bias-corrected bootstrapped standard errors. ${ }^{*} p<0.05$, ${ }^{* *} p<0.01,{ }^{* * *} p<0.001$.

While age $(\beta=-0.024)$ and gender $(\beta=-0.166)$ had a significant negative direct effect on risk tolerance, cognition score $(\beta=0.028)$ had a positive direct effect on risk tolerance. The results were consistent with findings from the previous studies $[13,14,17,18]$ where researchers found a negative association between being female and risk tolerance and reported lower risk tolerance for older individuals. Yao et al. [12] reported a decline in risk tolerance level with an increase in age, which mirrors our results. Results also showed that race, ethnicity, education, self-reported health status, and income had a direct effect on risk tolerance. White individuals $(\beta=-0.106)$ were less risk-tolerant than African-American people. Non-Hispanics $(\beta=-0.152)$ had a lower level of risk tolerance than Hispanic people. Individuals with college and above education $(\beta=0.221)$ were more risk-tolerant than individuals with less than a high school education. Similarly, results also indicated that individuals who reported excellent $(\beta=0.310)$ and good health $(\beta=0.172)$ had a higher level of risk tolerance than individuals with poor health status. 
Table 4. Indirect effect of age and gender on risk tolerance through cognition.

\begin{tabular}{lccc}
\hline & $\boldsymbol{\beta}$ & $\mathbf{9 5 \%}$ CI for $\boldsymbol{\beta}$ & Decision on Hypotheses \\
\hline Age $\rightarrow$ Cognition score $\rightarrow$ Risk tolerance & $-0.008^{*}$ & {$[-0.016,-0.001]$} & Supports Hypothesis 1 \\
Gender $\rightarrow$ Cognition score $\rightarrow$ Risk tolerance & 0.004 & {$[0.000,0.008]$} & Does not support Hypothesis 2 \\
\hline
\end{tabular}

Note. Confidence intervals $(\mathrm{CI})$ are based on bias-corrected bootstrapped standard errors. ${ }^{*} p<0.05$.

In addition, we tested the indirect effect (Table 4) of age and gender on risk tolerance through bias-corrected bootstrap standard errors. Results suggest the significant indirect effect of age $(\beta=-0.008)$ on risk tolerance through cognition and provide evidence in favor of the first alternate hypothesis that cognition mediates the relationship between age and risk tolerance. The true indirect effect of age was projected to lie between -0.016 and -0.001 at the $p<0.05$ level. About $25 \%$ of the total effect was found to be mediated by cognition, which is a respectable amount. Results indicate that the cognitive decline that occurs with aging partially lessens the risk tolerance level in the older population rather than the age alone. However, the indirect effect of gender through cognition was not significant. Results do not provide evidence to support the second hypothesis that cognition mediates the relationship between gender and risk tolerance.

Nevertheless, various aspects of cognition might mediate the relationship between gender and risk tolerance. Thus, focusing on different domains of cognition separately rather than considering the total cognition score as a mediator might be an area of future research. Similarly, there might be some other mechanisms that explain the gender difference in risk tolerance that could be further explored. For example, Lee et al. [27] studied sex-related differences in neural activity during risk taking using functional magnetic resonance imaging (FMRI) in younger participants. They found stronger activation of right insula and bilateral orbitofrontal cortex (OFC) in females as compared to their male counterparts while performing a risky gains task. Similar studies could be conducted in the aging population to further explain gender differences in risk tolerance.

\section{Discussion}

Empirical evidence exploring mechanisms underlying the age and gender differences in risk tolerance are scant. This study presented a decomposition of age and gender differences in risk tolerance. Results showed that an increase in age was associated with a lower level of risk tolerance, and $25 \%$ of this reduction was accounted for by cognitive functioning. We also found that women were associated with a lower level of risk tolerance. The negative relationship between older age and risk tolerance, and the association between gender difference and risk tolerance, are consistent with the previous literature $[13,14,28,29]$. However, the gender difference in risk tolerance was not explained by cognition. In a nutshell, in response to the hypothesis 1 , results support the hypothesized relationship indicating that cognitive functioning serves as a mediator explaining the relationship between age and risk tolerance.

In the current scenario of shifting demography, this research provides compelling insight for policy implications and financial practitioners. With an increase in the median age of the population and with people living longer, adequacy of retirement income has become a national concern [30]. Individuals need to take financial risks by investing into risky financial assets in the early stages of their life cycle so that they can save enough to sustain themselves through their remaining life expectancy in the post-retirement phase of their life [27]. Previous literature shows evidence of association between risk tolerance and savings and investment behavior [31]. Individuals who avoid investing in riskier asset classes, such as stocks and mutual investment funds, due to their lower level of risk tolerance, may not be able to build enough savings to contribute toward their retirement income that is sustainable through the course of their retirement. This issue is further exacerbated for aging households experiencing a decline in their cognitive functioning. Mental health status is therefore an important factor that contributes to greater risk tolerance and normative financial behavior that is associated with greater financial sustainability for 
households in retirement [29]. Understanding the contribution of cognitive functioning towards age differences in risk tolerance will be useful for financial planners when advising older clients. Additionally, financial planners and counselors could also encourage their older clients to participate in activities that keep them socially engaged and recommend activities that could help slow down the decline in cognitive functioning of their clients. Similarly, more can be done from a policy and programming standpoint at the community level. Policymakers can help with more funding or encourage private partnerships to help to design intervention strategies and implement policies that promote active and healthy lifestyles for older households and make fitness programs and cognitive health related information more accessible to the older population. Another area where public policy could play a role would be in increasing older adults' access to more community-based financial education programs that provide information related to personal finance, risk management, and portfolio management in retirement.

While this study adds to the literature by disentangling the direct and indirect effects of age and gender on risk tolerance through psychological measures, the following limitations should be acknowledged. First, the risk tolerance measure in the HRS dataset was based on a single item self-assessment question, which might not represent the full continuum of financial risk tolerance [32]. In addition, there might exist inconsistencies in the information provided with regard to subjective risk tolerance [33]. While the HRS question on risk tolerance provides useful information, additional questions on risk tolerance constructs might add invaluable information. Second, the study uses a single wave of the HRS and investigates the mediation on cross-sectional data; thus, results should be interpreted as the association among the factors studied, but they do not establish causal relations. Prospective studies need to include multiple waves to further examine causality among the factors under consideration.

Author Contributions: Conceptualization, M.S. and S.C.; methodology, M.S. and S.C.; formal analysis, M.S.; investigation, M.S.; data curation, M.S. and S.C.; writing—original draft preparation, M.S.; writing—review and editing, M.S. and S.C.; visualization, M.S.; supervision, S.C. All authors have read and agreed to the published version of the manuscript.

Funding: This research received no external funding.

Institutional Review Board Statement: Not Applicable.

Informed Consent Statement: Not Applicable.

Data Availability Statement: The information on projections can be found in U.S. Census Bureau website. https://www.census.gov/newsroom/press-releases/2018/cb18-41-population-projections. html (accessed on 7 September 2020). Please refer to the Health and Retirement Study Imputation of Cognitive Functioning Measures on the https://hrs.isr.umich.edu/sites/default/files/biblio/ COGIMPdd.pdf for a more detailed description of the measures and the imputation process.

Conflicts of Interest: The authors declare no conflict of interest.

\section{References}

1. Grable, J.E. Risk tolerance. In Handbook of Consumer Finance Research; Jiao, J.J., Ed.; Springer: New York, NY, USA, 2008 ; pp. 1-20.

2. Bucciol, A.; Zarri, L. The shadow of the past: Financial risk taking and negative life events. J. Econ. Psychol. 2015, 48, 1-16. [CrossRef]

3. Yao, R.; Hanna, S.D.; Lindamood, S. Changes in financial risk tolerance, 1983-2001. Financ. Serv. Rev. 2004, 13, 249.

4. Neelakantan, U. Estimation and impact of gender differences in risk tolerance. Econ. Inq. 2010, 48, 228-233. [CrossRef]

5. Burton, E.L. The impact of risk aversion on economic development in Portugal. Perspect. Bus. Econ. 2015, 33, 27-38.

6. Tavares, F.; Santos, E.; Tavares, V.; Ratten, V. The perception and knowledge of financial risk of the Portuguese. Sustainability 2020, 12, 8255. [CrossRef]

7. Dohmen, T.; Falk, A.; Golsteyn, B.; Huffman, D.; Sunde, U. Risk attitudes across the life course. Econ. J. 2017, 127, F95-F116. [CrossRef]

8. Blau, F.D.; Kahn, L.M. The US gender pay gap in the 1990s: Slowing convergence. Ilr Rev. 2006, 60, 45-66. [CrossRef]

9. Roszkowski, M.J.; Grable, J. Gender stereotypes in advisors' clinical judgments of financial risk tolerance: Objects in the mirror are closer than they appear. J. Behav. Financ. 2005, 6, 181-191. [CrossRef] 
10. Boyle, P.; Yu, L.; Buchman, A.; Bennett, D. Risk aversion is associated with decision making among community-based older persons. Front. Psychol. 2012, 3, 205. [CrossRef]

11. Grable, J.E. Financial risk tolerance and additional factors that affect risk taking in everyday money matters. J. Bus. Psychol. 2000, 14, 625-630. [CrossRef]

12. Yao, R.; Sharpe, D.L.; Wang, F. Decomposing the age effect on risk tolerance. J. Socio-Econ. 2011, 40, 879-887. [CrossRef]

13. Hallahan, T.A.; Faff, R.W.; McKenzie, M.D. An empirical investigation of personal financial risk tolerance. Financ. Serv. Rev. 2004, $13,57-78$.

14. Faff, R.; Hallahan, T.; McKenzie, M. Nonlinear linkages between financial risk tolerance and demographic characteristics. Appl. Econ. Lett. 2009, 16, 1329-1332. [CrossRef]

15. Booth, A.; Cardona-Sosa, L.; Nolen, P. Gender differences in risk aversion: Do single-sex environments affect their development? J. Econ. Behav. Organ. 2014, 99, 126-154. [CrossRef]

16. Borghans, L.; Heckman, J.J.; Golsteyn, B.H.; Meijers, H. Gender differences in risk aversion and ambiguity aversion. J. Eur. Econ. Assoc. 2009, 7, 649-658. [CrossRef]

17. Cupples, S.; Rasure, E.; Grable, J. Educational achievement as a mediator between gender and financial risk tolerance: An exploratory study. Ewha J. Soc. Sci. 2013, 29, 151-179. [CrossRef]

18. Gibson, R.J.; Michayluk, D.; Van de Venter, G. Financial risk tolerance: An analysis of unexplored factors. Financ. Serv. Rev. 2013, 22, 23-50.

19. Preacher, K.J.; Rucker, D.D.; Hayes, A.F. Addressing moderated mediation hypotheses: Theory, methods, and prescriptions. Multivar. Behav. Res. 2007, 42, 185-227. [CrossRef]

20. Salthouse, T.A. The processing-speed theory of adult age differences in cognition. Psychol. Rev. 1996, 103, 403. [CrossRef]

21. Van Hooren, S.; Valentijn, A.; Bosma, H.; Ponds, R.; Van Boxtel, M.; Jolles, J. Cognitive functioning in healthy older adults aged 64-81: A cohort study into the effects of age, sex, and education. Aging Neuropsychol. Cogn. 2007, 14, 40-54. [CrossRef]

22. McCarrey, A.C.; An, Y.; Kitner-Triolo, M.H.; Ferrucci, L.; Resnick, S.M. Sex differences in cognitive trajectories in clinically normal older adults. Psychol. Aging 2016, 31, 166. [CrossRef]

23. Van Exel, E.; Gussekloo, J.; De Craen, A.; Bootsma-Van Der Wiel, A.; Houx, P.; Knook, D.; Westendorp, R. Cognitive function in the oldest old: Women perform better than men. J. Neurol. Neurosurg. Psychiatry 2001, 71, 29-32. [CrossRef] [PubMed]

24. Wahlin, Å.; MacDonald, S.W.; de Frias, C.M.; Nilsson, L.-G.; Dixon, R.A. How do health and biological age influence chronological age and sex differences in cognitive aging: Moderating, mediating, or both? Psychol. Aging 2006, 21, 318. [CrossRef] [PubMed]

25. Kim, E.J.; Hanna, S.D.; Chatterjee, S.; Lindamood, S. Who among the elderly owns stocks? The role of cognitive ability and bequest motive. J. Fam. Econ. Issues 2012, 33, 338-352. [CrossRef]

26. Pak, T.-Y.; Chatterjee, S. Aging, overconfidence, and portfolio choice. J. Behav. Exp. Financ. 2016, 12, 112-122. [CrossRef]

27. Lee, T.M.; Chan, C.C.; Leung, A.W.; Fox, P.T.; Gao, J.-H. Sex-related differences in neural activity during risk taking: An fMRI study. Cereb. Cortex 2009, 19, 1303-1312. [CrossRef] [PubMed]

28. Bannier, C.E.; Neubert, M. Gender differences in financial risk taking: The role of financial literacy and risk tolerance. Econ. Lett. 2016, 145, 130-135. [CrossRef]

29. Roszkowski, M.J.; Grable, J.E. Gender differences in personal income and financial risk tolerance: How much of a connection? Career Dev. Q. 2010, 58, 270-275. [CrossRef]

30. Cocco, J.F.; Gomes, F.J. Longevity risk, retirement savings, and financial innovation. J. Financ. Econ. 2012, 103, 507-529. [CrossRef]

31. Magendans, J.; Gutteling, J.M.; Zebel, S. Psychological determinants of financial buffer saving: The influence of financial risk tolerance and regulatory focus. J. Risk Res. 2017, 20, 1076-1093. [CrossRef]

32. Lucarelli, C.; Uberti, P.; Brighetti, G. Misclassifications in financial risk tolerance. J. Risk Res. 2015, 18, 467-482. [CrossRef]

33. Kochaniak, K.; Ulman, P. Risk-Intolerant but Risk-Taking-Towards a Better Understanding of Inconsistent Survey Responses of the Euro Area Households. Sustainability 2020, 12, 6912. [CrossRef] 